\title{
Review about gabapentin misuse, interactions, contraindications and side effects
}

\author{
Gabriel C Quintero \\ Florida State University - Republic of \\ Panama, Clayton, Panama
}

This article was published in the following Dove Press journal:

Journal of Experimental Pharmacology

9 February 2017

Number of times this article has been viewed

\begin{abstract}
The current work is targeted to review the risks of gabapentin misuse, its potential interactions with other drugs, side effects and use contraindications. This review consists of a total of 99 biographical references (from the year 1983 to 2016). A publication search of PubMed was performed from January 1983 to December 2016. It included animal studies, clinical studies, case studies and reviews related to gabapentin misuse, potential interactions, side effects and use contraindications. The search terms were gabapentin, anticonvulsant and antiepileptic. In general, it seems that gabapentin has risks of being misused based on the increased level of prescriptions, related fatalities, recreational misuse and higher doses of self-administration. The main reasons for gabapentin misuse are as follows: getting high, alleviating opioid withdrawal symptoms and potentiating methadone effects. Some of the main substances that interact with gabapentin are morphine, caffeine, losartan, ethacrynic acid, phenytoin, mefloquine and magnesium oxide. Some of the side effects caused by gabapentin are teratogenicity, hypoventilation, respiratory failure and myopathy. Finally, reports in general contraindicate the use of gabapentin in conditions such as myasthenia gravis and myoclonus.
\end{abstract}

Keywords: gabapentin, misuse, interactions, contraindications, side effects

\section{Introduction}

\section{Methodological procedure of the review}

The current review consists of a total of 99 biographical references (from the year 1983 to 2016). A publication search of PubMed was performed from January 1983 to December 2016. It included animal studies, clinical studies, case studies and reviews related to gabapentin misuse, interactions, toxicology and pharmacological description of gabapentin. The search terms included were gabapentin, anticonvulsant and antiepileptic.

\section{Basic information of gabapentin}

Gabapentin is a pharmaceutical drug that has a white solid (small crystals) physical appearance. The molecular formula of gabapentin is $\mathrm{C}_{9} \mathrm{H}_{17} \mathrm{NO}_{2}$, and it has a formula weight of $171.23678 \mathrm{~g} / \mathrm{mol}$. It has diverse brand names such as Gralise, Neurontin, Fanatrex and Horizant (National Center for Biotechnology Information). Commercially, gabapentin can be obtained in the forms of capsules or tablets of diverse doses (capsules: 100, 300 and $400 \mathrm{mg}$; tablets: 300, 600 and $800 \mathrm{mg}$; webpage of the United States National Library of Medicine). 
Gabapentin has various pharmacokinetic and pharmacodynamic properties. ${ }^{1}$ Compared to pregabalin, gabapentin is absorbed slowly after oral administration, and it has an utmost level in plasma within 3-4 hours. Besides this, oral administration of gabapentin has a saturable absorption (a nonlinear process, zero order). ${ }^{1}$ Furthermore, the plasma level of gabapentin does not increase proportionally if its dosages are increased; gabapentin does not attach to plasma proteins. ${ }^{1}$ Gabapentin is neither inhibited nor metabolized by hepatic enzymes; besides, gabapentin can be expelled by the renal system, and its excretion half-life is roughly 6 hours. ${ }^{1}$

\section{Mechanisms of action of gabapentin}

Gabapentin is an anticonvulsant drug that reduces synaptic transmission by decreasing presynaptic voltage-gated $\mathrm{Ca}^{2+}$ and $\mathrm{Na}^{+}$channels. ${ }^{2-4}$ Besides, gabapentin reduces exocytosis and the discharge of neurotransmitter from presynaptic terminals. ${ }^{5,6}$ On the other hand, another line of research reported that gabapentin decreases the formation of excitatory synapses by acting on $\alpha 2-\delta 1$ subunit of calcium channels. ${ }^{7,8}$ Besides, complementary research pointed out that gabapentin has specific affinity for $\alpha 2-\delta 1$ subunit, lower affinity for $\alpha 2-\delta 2$ subunit and non-affinity for $\alpha 2-\delta 3$ subunits. ${ }^{9}$

Research about the effects of gabapentin on gamma-aminobutyric acid (GABA) neurotransmitter levels has reported inconsistent results, i.e., increase in GABA levels based on human studies, ${ }^{10}$ but no effects have been reported in in vitro studies. ${ }^{11}$ Moreover, gabapentin affects $\operatorname{GABA}(\mathrm{A})$, but not $\mathrm{GABA}(\mathrm{B})$ receptor responses, based on in vitro studies. ${ }^{11,12}$

Another study reported that gabapentin did not modify the level of glutamate, a neurotransmitter, according to human studies. ${ }^{10}$ Moreover, studies have reported about the antagonistic effects of gabapentin on $N$-methyl-D-aspartate (NMDA) glutamatergic receptors ${ }^{13}$ and protein kinase $\mathrm{C}-$ extracellular signal-regulated kinase 1/2 (PKC-ERK1/2) pathways. ${ }^{14}$ Finally, it has also been reported that gabapentin did not influence the activities of glycine receptors and G-protein-coupled inwardly rectifying potassium (GIRK) channels. $^{13}$

\section{Gabapentin use in experimentation}

Gabapentin has been used in basic and clinical investigation for the past few decades. ${ }^{15-18}$ Initially, research was focused on the treatment of epilepsy. ${ }^{19,20}$ Later it was explored for treating other ailments such as problems of conduct control and mental health ailments, ${ }^{21,22}$ amyotrophic lateral sclerosis, ${ }^{23}$ reduction of pain, ${ }^{24,25}$ anxiety, ${ }^{26}$ neuralgia, ${ }^{27}$ restless legs syndrome, ${ }^{28,29}$ bipolar disorder ${ }^{30}$ and other disorders. ${ }^{31}$
However, it is necessary to consider that the study about the alleviation of behavioral dyscontrol after the use of gabapentin was based on a case study $(n=1)$; it reported on a 13-year-old boy, and the reliability was limited because of the small sample size. ${ }^{21}$

Moreover, the study about the reduction in pain after the use of gabapentin was based on a clinical study of four subjects, and the majority of these subjects (three out of four) were in the age range of 50-82 years; ${ }^{25}$ finally, another clinical study about the alleviation of neuralgia after the use of gabapentin consisted of a very small sample size $(n=1, a$ 78-year-old woman). ${ }^{27}$ It is important to consider the limitations of the reliability based on these small sample sizes and the restricted ranges of ages.

The main purpose of the current work is to present an updated review about the problems related to gabapentin misuse, side effects, interactions with other drugs and use contraindications.

\section{Problems related to misuse, abuse or dependence on gabapentin}

Case clinical and large group studies suggest that gabapentin can be abused and induce health problems. ${ }^{32-37}$ Specifically, a study by Smith et $\mathrm{al}^{\mathrm{l}^{37}}$ showed that gabapentin has been misused (nonmedical use) in an adult sample from the Appalachian Kentucky ( $\mathrm{n}=503)$. Specifically, it was reported that $15 \%$ of the subjects used gabapentin for getting high in the previous 6 months; this percentage represented a $165 \%$ increase compared to a similar study of the previous year. In addition, the participants reported the use of gabapentin an average of 25 days out of the 30 previous days. Furthermore, the two major sources of gabapentin were physicians $(52 \%)$ and drug dealers (36\%), and street costs were reported to be less than US $\$ 1.00$ per pill. ${ }^{37}$ In general, the methodology of this study was solid (described in more detail in another publication of the same group ${ }^{38}$ ); the mental health aspects (including substance misuse) were assessed by trained staff using the Mini International Neuropsychiatric Interview (version 5.0), and the Diagnostic and Statistical Manual of Mental Disorders (DSM) IV criteria were used for the purpose of classification. ${ }^{38}$

On the other hand, the reliability of the clinical study by Kruszewski et a ${ }^{35}$ about gabapentin dependence is discrete, because it was based on a very small sample size $(n=1$, a 38-year-old male); moreover, the patient of this study received gabapentin under off-label prescription. On the other hand, the human investigation that reported gabapentin abuse consisted of a small number of males $(n=5)$, ranging from 
29 to 45 years of age ${ }^{36}$ in addition, they were inmates in a prison and they sniffed gabapentin powder from capsules. Hence, there are limitations for generalizing these findings to a broader population because of the small sample size and the special group reported (inmates).

A study by Baird et $\mathrm{al}^{39}$ in Scotland used a questionnaire-based survey $(n=129)$ for exploring gabapentinoids (gabapentin and pregabalin) and other substance abuse. The investigation reported that $22 \%$ of participants $(29 / 129)$ showed gabapentinoid abuse. Furthermore, a significant portion of these subjects $(38 \%, 11 / 29)$ abused gabapentinoids for potentiating the dose of methadone. An analysis of the information showed that approximately one-fifth of the participants $(25,19 \%)$ employed gabapentin without prescription. A limitation of this study was the lack of validation of the questionnaire employed.

Another study evaluated the misuse of gabapentin based on the analysis of information posted in web pages. ${ }^{40}$ It included monitoring of posted information on a daily, weekly or monthly basis (depending on the relevance of the content). For the initial search criteria, the study searched on eight European languages (English, German, Spanish, Italian, Dutch, Norwegian, Finnish and Swedish). Regarding the information posted about gabapentin in the web sites, these were some of the descriptions: ${ }^{40}$

- Gabapentin has powerful sedative and psychedelic effects.

- Gabapentin was sold on the web without the need of a medical prescription.

- It is a very complete pharmaceutical substance, and its effects are like super amphetamine rush.

- Gabapentin can induce dissociations such as those found on dextromethorphan (only on head and hands).

- Gabapentin helps in becoming very active, friendly, talkative and disinhibited.

- Gabapentin can be combined with other drugs such as baclofen, cannabis, alcohol, selective serotonin reuptake inhibitors, lysergic acid diethylamide, amphetamine and gamma-hydroxybutyric acid.

Some of the limitations in this study were as follows: ${ }^{40}$ the omission of other languages (for instance, Portuguese, Japanese and others in Asia and Africa) for the initial screen of web pages (hence, overlooking some studies). Moreover, because it relied more on the information posted on web pages, it is difficult to verify the veracity of the statements posted on the web. For instance, there is an absence of any questionnaire or biographical data confirming the participants' health status. This study can be considered more a descriptive study (qualitative) rather than a quantitative study, making it impossible to have a statistical index of reference.

A study in Scotland (Tayside region) reported an increase in the number of patients asking for gabapentin and in the number of prescriptions released. ${ }^{32}$ Moreover, it was reported that from those subjects attending misuse services for at least 4 years $(n=252), 5.2 \%$ had a prescription for gabapentin (average dose of $1343 \mathrm{mg}$ ). In addition, these subjects were at least three times more likely to accept the misuse of analgesics $(P=0.006){ }^{32}$

A Finnish study investigated all the cases in which pregabalin or gabapentin was found in postmortem toxicology analysis of medicolegal deaths (years 2010 and 2011). ${ }^{41}$ Gabapentin was found in 43 cases. Moreover, drug abuse was associated with $18.6 \%$ of the gabapentin findings. Gabapentin poisoning accounted for $4.7 \%$ of all the gabapentin-related deaths. For those with drug abuse problems, $12.5 \%$ showed gabapentin poisoning.

Finally, in the gabapentin abuser group, $87.5 \%$ of the cases showed concomitant opioid use. ${ }^{41}$ As a reference, some authors consider that pregabalin is more addictive than gabapentin because of pregabalin's rapid absorption and faster onset of action. ${ }^{41}$

On the other hand, a descriptive analysis of a database cases (EudraVigilance) about gabapentin misuse, dependence or abuse (years 2004-2015) was performed by Chiappini and Schifano, ${ }^{42}$ which reported $4.8 \%$ of gabapentin misuse, dependence or abuse; subjects were mainly women. A total of 86 gabapentin fatalities were found, and the majority consisted of a combination of gabapentin and opioids.

Moreover, another investigation on former inmates $(\mathrm{n}=250)$ found a $16 \%$ lifetime prevalence of gabapentin misuse. ${ }^{43}$ Furthermore, a strong relationship between opioid use disorder and gabapentin abuse was found; specifically, $26 \%$ of patients with opioid use disorder reported gabapentin abuse, but only $4 \%$ of patients without the opioid use disorder reported gabapentin nonmedical use.

Finally, an Internet survey (UK, n=1500) evaluated the lifetime prevalence and frequency of gabapentin misuse. ${ }^{44}$ The researchers found a $1.1 \%$ lifetime prevalence of gabapentin misuse.

\section{Side effects caused by gabapentin}

If a clinician is planning to employ gabapentin for treating a drug-related problem, it is necessary to consider its potential side effects. A review of different studies describes side effects such as teratogenic effects (rodent studies), ${ }^{45-47}$ central hypoventilation and/or respiratory failure, ${ }^{48,49}$ deficits 
in visual field, ${ }^{50}$ myopathy, ${ }^{51,52}$ self-harm or suicidal behavior, ${ }^{53-56}$ mitochondrial toxicity, ${ }^{57}$ somnolence, dizziness and diarrhea ${ }^{58}$ however, other studies in nonhuman species ${ }^{59}$ and human beings ${ }^{60}$ did not find teratogenic effects (this topic is discussed further at the end of this section). Nevertheless, the studies that reported gabapentin induction of central hypoventilation were clinical studies with small sample sizes $\left(\mathrm{n}=1\right.$, a 74 -year-old female, ${ }^{48}$ and $\mathrm{n}=1$, a 69 -year-old male) $;{ }^{49}$ therefore, the reliability of these findings is discrete.

Also, the clinical study that reported visual field defects induced by gabapentin included a very small sample size ( $\mathrm{n}=1$, a 52-year-old woman), implicating limitations on reliability. ${ }^{50}$

The studies that reported myopathy caused by gabapentin also have a small sample size $\left(n=1\right.$, an 85 -year-old female ${ }^{51}$ and $n=2^{52}$ ); then, the reliability of these findings is discrete. Finally, the study about self-harm and suicidal behavior induced by gabapentin has to be considered with discretion, because it was a single case study $(n=1$, a 21 -year-old male). ${ }^{53}$

Another set of studies did not find teratogenic effects of gabapentin; specifically, an investigation evaluated the effects of gabapentin across different species (mice, rat and rabbits). Gabapentin was administered during gestation, and it was not teratogenic in mice (up to $3000 \mathrm{mg} / \mathrm{kg}$ ) and rats (up to $1500 \mathrm{mg} / \mathrm{kg}$ ); in the rabbit group, some effects were found (one died, four aborted, reduced food consumption and body weight gain) at the $1500 \mathrm{mg} / \mathrm{kg}$ dose, but the author concluded that there were no teratogenic effects. Another study in pregnant women $(n=44)$ found no differences compared to the general population or women with epilepsy in terms of maternal complication, cesarean section, miscarriage, low birth weight or malformation. ${ }^{60}$

Some limitations of the studies about Gabapentin and teratogenicity have been the small sample size, ${ }^{61,62}$ and the use of multiple drugs (medical polydrug regimen) in the studies; these factors limit the generalization of the results. ${ }^{62}$ Moreover, as personal opinion, the teratogenic effects can be observed not only at gestation or early postnatal stages but also at later stages (for instance, adolescence), and these later stages should be explored in future research. As a reference, a review cited a study about altered cognitive function after early postnatal stage caused by gabapentin. ${ }^{62}$

On the other hand, a recent review by Verrotti et al ${ }^{61}$ suggested an important distinction between old and new antiepileptic drugs in terms of teratogenicity: new antiepileptic (such as gabapentin) drugs have a low risk of major congenital malformations compared to old antiepileptic drugs.
Another review about clinical trials of gabapentin stated that the most common side effects of gabapentin were somnolence $(20 \%)$, dizziness $(18 \%)$, ataxia $(13 \%)$ and fatigue (11\%). ${ }^{63}$ Moreover, another large study that used gabapentin as adjunctive therapy for seizure control reported that the most common side effects were somnolence (15.2\%), dizziness $(10.9 \%)$ and asthenia $(6.0 \%) .{ }^{64}$

Finally, some authors consider that higher doses of gabapentin can be used and its side effects can be still avoided; ${ }^{65}$ the variations in the effects of gabapentin can depend more on the route of administration. ${ }^{66,67}$

\section{The interactions between gabapentin and other drugs Lack of interactions between gabapentin and other drugs}

Different research studies have stated that gabapentin could either interact or lack interactions with other drugs. In general, some studies have shown that gabapentin is an antiepileptic drug with a low profile of interaction with other drugs. ${ }^{6,69}$ Specifically, a general review stated that gabapentin lacks interactions with hepatic enzymes, plasma proteins and other drugs; these factors make gabapentin suitable for elderly patients suffering from hepatic diseases. ${ }^{68}$ Furthermore, a review about drug combinations for treating epilepsy concluded that gabapentin did show a low profile of pharmacokinetic and pharmacodynamic interactions with other antiepileptic drugs. ${ }^{69}$

Another review about drug combinations for alleviating epilepsy concluded that gabapentin has a more favorable pharmacokinetic profile, but it is not totally exempt from interactions with other drugs. ${ }^{70}$ Moreover, these authors also concluded that gabapentin can be useful for particular patient groups such as patients with cancer, transplants, anticoagulant treatments and HIV infection. ${ }^{70}$ Finally, another review about drug combinations for alleviating epilepsy concluded that gabapentin is a drug with few interactions because of its pharmacokinetic characteristics; gabapentin has low binding to blood albumin, renal excretion or metabolization (by noncytochrome P450 or uridine glucuronyl transferases). ${ }^{71}$

On the other hand, a mice study reported that the combinations of gabapentin with antidiuretic drugs (such as ethacrynic acid and hydrochlorothiazide) do not alter the anticonvulsant activity of gabapentin (either single or chronic doses of antidiuretics)..$^{72}$

Moreover, other experimental studies showed the lack of pharmacokinetic interactions between gabapentin and 
contraceptive drugs (norethindrone acetate and ethinyl estradiol $)^{73}$ and antiepileptic drugs (valproate, carbamazepine $^{74}$ and phenobarbitone ${ }^{75}$ ). Another study confirmed that gabapentin lacks pharmacokinetic interaction but shows pharmacodynamic interaction with the antiepileptic drug topiramate. $^{76}$

Finally, a study on the interactions between gabapentin and morphine reported inconsistent results. Specifically, a rodent study reported lack of pharmacokinetic interactions, ${ }^{77}$ but other rodent studies showed the presence of pharmacodynamic interactions (behavioral synergism) ${ }^{78}$ However, other human investigations showed pharmacokinetic and pharmacodynamic interactions between morphine and gabapentin. ${ }^{79}$

\section{Remarkable interactions between gabapentin and other drugs}

Other investigations probed the interactions between gabapentin and others drugs. For instance, a mice study reported motor impairment because of the interactions between gabapentin and losartan. ${ }^{80}$ Another mouse study reported disruption of motor performance (based on the chimney test) because of the interactions between gabapentin and ethacrynic acid (diuretic drug). ${ }^{72}$

Moreover, different clinical studies have reported interactions between gabapentin and morphine, and a further induction of side effects. ${ }^{81,82}$ Specifically, a clinical study $(n=1)$ stated that this interaction induced somnolence, chorea, spatiotemporal disorientation, visual hallucinations and a single episode of psychosis. ${ }^{81}$ However, the generalization of this finding to a broader population is discrete because of the very small sample size ( $\mathrm{n}=1$, an 82 -year-old female) ${ }^{81}$ Another study by a German group reported that volunteers who received the combination of gabapentin and morphine showed a higher number of side effects compared to other subjects who received either drug alone, but this tendency did not reach significant levels; the most marked side effects observed in this study were somnolence, dizziness and nausea. ${ }^{82}$

Basic and clinical studies have shown that gabapentin's anticonvulsant properties can be modified because of the interaction with other drugs. For instance, the combination with caffeine can reduce gabapentin's anticonvulsant effects. ${ }^{83,84}$ Furthermore, caffeine was able to decrease the electroconvulsive threshold, previously augmented by gabapentin at a $200 \mathrm{mg} / \mathrm{kg}$ dose; the rise in threshold induced by another dose of gabapentin $(23.1 \mathrm{mg} / \mathrm{kg})$ can only be decreased by the administration of chronic caffeine. ${ }^{83}$ Moreover, another mice study found that the administration of acute or chronic caffeine $(0.12-0.24 \mathrm{mmol} / \mathrm{kg})$ decreased the protective potential of gabapentin. ${ }^{84}$ These studies together suggest a more strict monitoring of caffeine intake by epileptic patients.

On the other hand, another mouse study showed that carvedilol (a beta-adreno receptor antagonist) can also interact with gabapentin, augmenting its anticonvulsive activity; ${ }^{82}$ this suggests a potential useful combination for treating epilepsy. The other mice studies reported a reduction in gabapentin anticonvulsant efficacy after the combination with the antidepressant drug, sertraline. ${ }^{85}$

Other studies have shown that the interactions between gabapentin and other drugs can be useful for alleviating pain problems. For instance, the combination of lower doses of gabapentin and tramadol can synergistically decrease the experience of pain; moreover, this analgesic effect is dose dependent when administered locally, spinally or orally. ${ }^{83}$ In effect, this combination can reverse formalin-induced nociception, and it can be useful for clinical treatment of inflammatory pain. ${ }^{83}$ Another rat study found a synergistic interaction between gabapentin and metamizol in the rat formalin test; specifically, the oral administration of both drugs dose-dependently decreased flinching behavior during the second phase of the formalin test; this suggests to explore further the combination of gabapentin and metamizol for alleviating human inflammatory pain. ${ }^{84}$

Other clinical studies showed interactions between gabapentin and other antiepileptic drugs such as phenytoin, ${ }^{86}$ and mefloquine. ${ }^{87}$ One of the effects of mefloquine in the nervous system is to block gap junction synapses. ${ }^{88}$ Nevertheless, because the phenytoin study cited was a single clinical case study (a 26-year-old male), its reliability is discrete. ${ }^{86}$

In addition, the interaction between gabapentin and antacid substances such as magnesium oxide ${ }^{89}$ and cimetidine has been demonstrated; ${ }^{90}$ specifically, cimetidine reduced $12 \%$ of gabapentin's clearance by decreasing its glomerular filtration rate ${ }^{90}$ (as a reference, cimetidine is an antagonist of the histamine $\mathrm{H} 2$ receptor, reducer of stomach acid production and an adjunctive therapy candidate for treating the early stage of Lyme disease ${ }^{91}$ ).

Finally, other medical drugs that interact with gabapentin are naproxen ${ }^{92}$ (nonselective nonsteroidal anti-inflammatory ${ }^{93}$ ) and sevelamer ${ }^{94}$ (a reducer of serum uric acid concentrations in hemodialysis patients ${ }^{95}$ ); as a reference, the interaction between sevelamer and gabapentin is moderate, and the main consequence is a decrease in gabapentin effects. $^{94}$ 


\section{Some contraindications for gabapentin use in patients with muscular problems}

Some reports have warned about the use of gabapentin in patients with myasthenia gravis ${ }^{96}$ or myoclonus problems. ${ }^{97}$ Specifically, a clinical study reported symptoms similar to those found in the myasthenia gravis (ocular weakness, facial weakness, masticatory weakness, fatigue and elevated level of acetylcholine receptor antibodies in the serum) after gabapentin treatment $\left(400 \mathrm{mg} /\right.$ day). ${ }^{96}$ Moreover, the patient improved his health after pyridostigmine therapy and gabapentin withdrawal. This suggests that gabapentin could worsen the symptoms of patients with myasthenia gravis. In a rat study, ${ }^{96}$ the rats underwent experimental autoimmune myasthenia gravis or control treatments and received gabapentin $(150 \mathrm{mg} / \mathrm{kg})$. After gabapentin treatment, the rats of the experimental group showed a decrease in electrophysiological responses (amplitude ratio after repetitive nerve stimulation) compared to control rats. ${ }^{96}$

Another human study reported worsening or onset of myoclonus after gabapentin treatment (1.9\%). ${ }^{97}$ Specifically, these patients experienced development or worsening of myoclonus within 2 weeks after starting gabapentin treatment. The doses related to these problems ranged from 600 to $1800 \mathrm{mg}$. After the discontinuation of gabapentin or clonazepam regimen, the myoclonus ceased without major consequences. $^{97}$

\section{General conclusions}

Conclusions about problems related to misuse, abuse or dependence to gabapentin

Individual clinical studies and large sample studies reported that gabapentin can be misused or abused and can generate general health problems. Different reasons for an inadequate use of gabapentin are as follows: motivation for getting "high", alleviation of opioid withdrawal symptoms and potentiating a methadone high. A strong relationship between opioid use disorder and gabapentin abuse has been reported (a study in former inmates). ${ }^{43}$ Problems related to the inadequate use of gabapentin can lead to toxicity and death (Finnish study ${ }^{41}$ ).

The prevalences of problems related to gabapentin use described in different studies are in the range of 1.1-19\%: 1.1\% lifetime misuse (online UK survey), ${ }^{44} 4.8 \%$ misuse/abuse or dependence (EudraVigilance database), ${ }^{42} 15 \%$ misuse (Appalachian study in Kentucky), ${ }^{37} 16 \%$ misuse (former inmates) ${ }^{43}$ and $19 \%$ use without prescription (Scotland study). ${ }^{39}$

\section{Conclusions about the side effects caused by gabapentin}

Some of the side effects related to gabapentin are teratogenicity, hypoventilation, respiratory failure, deficits in visual field, myopathy, self-harm behavior, suicidal behavior, mitochondrial toxicity, somnolence, dizziness and asthenia. The gabapentin route of administration is a relevant factor influencing side effects.

Nevertheless, another set of studies has reported the absence of teratogenic effects of gabapentin; ;9,60 additional investigations with larger sample sizes and screening teratogenic effects in posterior developmental stages are necessary (e.g., after early postnatal development). It is also necessary to conduct further studies with larger sample sizes on the effects of gabapentin on visual field defect, risks of misuse, myopathy, self-harm and suicidal behavior; the related studies so far have been mainly with small sample sizes.

\section{Conclusions about the interactions between gabapentin and other drugs}

The studies about gabapentin interactions showed varied results. Different reports suggest that gabapentin has a low profile of interaction with other drugs, ${ }^{68,69}$ hepatic enzymes ${ }^{68}$ and plasma proteins. ${ }^{69}$ In addition, gabapentin is recommended for special groups such as elderly patients suffering from hepatic diseases ${ }^{68}$ patients with cancer, and others. ${ }^{70}$

On the other hand, different investigations have reported that gabapentin could show interactions with other drugs such as losartan ${ }^{80}$ and ethacrynic acid $^{72}$ and induce motor impairment (mice studies). In addition, gabapentin can interact with caffeine and diminish its anticonvulsant effects (mice studies). ${ }^{83,84}$ Gabapentin can interact synergistically with tramadol or metamizol for alleviating pain. In addition, gabapentin can interact with antiepileptic drugs (phenytoin, mefloquine) ${ }^{86,87}$ antacids (magnesium oxide, cimetidine), ${ }^{89,90}$ nonselective nonsteroidal anti-inflammatory drugs (naproxen), ${ }^{92}$ reducer of serum uric acid concentrations (sevelamer) and morphine.

\section{Conclusions about some contraindications for gabapentin use}

Some clinical studies have warned about the use of gabapentin in conditions such as myasthenia gravis ${ }^{96}$ and myoclonus problems; ${ }^{97}$ even, gabapentin can induce symptoms similar to myasthenia gravis (ocular-facial-masticatory weaknesses, fatigue, and others). ${ }^{96}$ In addition, a basic mice study reported that rodents with an experimentally induced myasthenia 
gravis experienced changes in electrophysiological responses after gabapentin treatment. ${ }^{96}$ Another clinical study suggests that gabapentin can induce or worsen myoclonus. ${ }^{97}$

\section{Summary of conclusions}

The main reasons for gabapentin misuse are getting "high", alleviating opioid withdrawal and potentiating methadone. The prevalence of problems related to gabapentin use ranges from $1.1 \%$ to $19 \%$. Gabapentin inadequate use can lead to toxicity and mortality.

Gabapentin can induce diverse side effects such as teratogenicity, hypoventilation, respiratory failure, deficits in visual field, myopathy, self-harm behavior, suicidal behavior, mitochondrial toxicity, somnolence, dizziness and asthenia; these can be related to the route of administration. However, it seems necessary to conduct more studies with larger sample sizes for confirming these effects.

Gabapentin can interact with losartan, ethacrynic acid, caffeine, phenytoin, mefloquine, magnesium oxide, cimetidine, naproxen, sevelamer and morphine. Gabapentin use is contraindicated in patients with myasthenia gravis or myoclonus.

\section{Acknowledgments}

This work was funded by the SNI (Sistema Nacional de Investigación - National System of Investigation), contract 106-2015 (awarded to GCQ). The SNI is a department that belongs to the SENACYT (Secretaría Nacional de Ciencia, Tecnologia e Innovación - National Secretariat of Science, Technology and Innovation). SENACYT is physically located in the Republic of Panama.

\section{Disclosure}

The author reports no conflicts of interest in this work.

\section{References}

1. Bockbrader HN, Wesche D, Miller R, Chapel S, Janiczek N, Burger P. A comparison of the pharmacokinetics and pharmacodynamics of pregabalin and gabapentin. Clin Pharmacokinet. 2010;49(10):661-669.

2. Dickenson AH, Ghandehari J. Anticonvulsants and anti-depressants. Handb Exp Pharmacol. 2007;(177):145-177.

3. Landmark CJ. Targets for antiepileptic drugs in the synapse. Med Sci Monit. 2007;13:RA1-RA7.

4. Rogawski MA, Loscher W. The neurobiology of antiepileptic drugs. Nat Rev Neurosci. 2004;5:553-564.

5. Coderre TJ, Kumar N, Lefebvre CD, Yu JS. A comparison of the glutamate release inhibition and anti-allodynic effects of gabapentin, lamotrigine, and riluzole in a model of neuropathic pain. J Neurochem. 2007;100(5):1289-1299.

6. Cunningham MO, Woodhall GL, Thompson SE, Dooley DJ, Jones RS. Dual effects of gabapentin and pregabalin on glutamate release at rat entorhinal synapses in vitro. Eur J Neurosci. 2004;20(6):1566-1576.
7. Eroglu CAN, Susman MW, O'Rourke NA, et al. Gabapentin receptor a2d-1 is a neuronal thrombospondin receptor responsible for excitatory CNS synaptogenesis. Cell. 2009;139:380-392.

8. Bauer CS, Tran-Van-Minh A, Kadurin I, Dolphin AC. A new look at calcium channel $\alpha 2 \delta$ subunits. Curr Opin Neurobiol. 2010;20:1-9.

9. Marais E, Klugbauer N, Hofmann F. Calcium channel alpha(2) delta subunits-structure and Gabapentin binding. Mol Pharmacol. 2001;59(5):1243-1248.

10. Cai K, Nanga RP, Lamprou L, et al. The impact of gabapentin administration on brain GABA and glutamate concentrations: a 7T (1)H-MRS study. Neuropsychopharmacology. 2012;37(13):2764-2771.

11. Jensen AA, Mosbacher J, Elg S, et al. The anticonvulsant gabapentin (neurontin) does not act through gamma-aminobutyric acid-B receptors. Mol Pharmacol. 2002;61(6):1377-1384.

12. Lanneau C, Green A, Hirst WD, et al. Gabapentin is not a GABAB receptor agonist. Neuropharmacology. 2001;41(8):965-975.

13. Hara K, Sata T. Inhibitory effect of gabapentin on N-methyl-D-aspartate receptors expressed in Xenopus oocytes. Acta Anaesthesiol Scand. 2007;51(1):122-128.

14. Zhang YB, Guo ZD, Li MY, et al. Gabapentin effects on PKC-ERK1/2 signaling in the spinal cord of rats with formalin-induced visceral inflammatory pain. PLoS One. 2015;10(10):e0141142.

15. Hengy H, Kolle EU. Determination of gabapentin in plasma and urine by high-performance liquid chromatography and pre-column labelling for ultraviolet detection. J Chromatogr. 1985;341(2):473-478.

16. Vollmer KO, von Hodenberg A, Kolle EU. Pharmacokinetics and metabolism of gabapentin in rat, dog and man. Arzneimittelforschung. 1986;36(5):830-839.

17. Reimann W. Inhibition by GABA, baclofen and gabapentin of dopamine release from rabbit caudate nucleus: are there common or different sites of action? Eur J Pharmacol. 1983;94(3-4):341-344.

18. Schlicker E, Reimann W, Gothert M. Gabapentin decreases monoamine release without affecting acetylcholine release in the brain. Arzneimittelforschung. 1985;35(9):1347-1349.

19. Bartoszyk GD, Hamer M. The genetic animal model of reflex epilepsy in the Mongolian gerbil: differential efficacy of new anticonvulsive drugs and prototype antiepileptics. Pharmacol Res Commun. 1987;19(6): $429-440$.

20. Crawford P, Ghadiali E, Lane R, Blumhardt L, Chadwick D. Gabapentin as an antiepileptic drug in man. J Neurol Neurosurg Psychiatry. 1987;50(6):682-686.

21. Ryback R, Ryback L. Gabapentin for behavioral dyscontrol. Am J Psychiatry. 1995;152(9):1399.

22. Walden J, Hesslinger B. Value of old and new anticonvulsants in treatment of psychiatric diseases. Fortschr Neurol Psychiatr. 1995;63(8): $320-335$.

23. Welty DF, Schielke GP, Rothstein JD. Potential treatment of amyotrophic lateral sclerosis with gabapentin: a hypothesis. Ann Pharmacother. 1995;29(11):1164-1167.

24. Shimoyama M, Shimoyama N, Inturrisi CE, Elliott KJ. Gabapentin enhances the antinociceptive effects of spinal morphine in the rat tailflick test. Pain. 1997;72(3):375-382.

25. Rosner H, Rubin L, Kestenbaum A. Gabapentin adjunctive therapy in neuropathic pain states. Clin J Pain. 1996;12(1):56-58.

26. Singh L, Field MJ, Ferris P, et al. The antiepileptic agent gabapentin (Neurontin) possesses anxiolytic-like and antinociceptive actions that are reversed by D-serine. Psychopharmacology (Berl). 1996;127(1):1-9.

27. Segal AZ, Rordorf G. Gabapentin as a novel treatment for postherpetic neuralgia. Neurology. 1996;46(4):1175-1176.

28. Mellick GA, Mellick LB. Management of restless legs syndrome with gabapentin (Neurontin). Sleep. 1996;19(3):224-226.

29. Adler $\mathrm{CH}$. Treatment of restless legs syndrome with gabapentin. Clin Neuropharmacol. 1997;20(2):148-151.

30. Ryback RS, Brodsky L, Munasifi F. Gabapentin in bipolar disorder. J Neuropsychiatry Clin Neurosci. 1997;9(2):301.

31. Gabapentin and pregabalin: abuse and addiction. Prescrire Int. 2012;21(128):152-154. 
32. Smith BH, Higgins C, Baldacchino A, Kidd B, Bannister J. Substance misuse of gabapentin. Br J Gen Pract. 2012;62(601):406-407.

33. Spence D. Bad medicine: gabapentin and pregabalin. BMJ. 2013; 347:f6747.

34. Maskell PD. Gabapentin and pregabalin abuse by heroin users. Br Med J. 2013;347:f6747.

35. Kruszewski SP, Paczynski RP, Kahn DA. Gabapentin-induced delirium and dependence. J Psychiatr Pract. 2009;15(4):314-319.

36. Reccoppa L, Malcolm R, Ware M. Gabapentin abuse in inmates with prior history of cocaine dependence. Am J Addict. 2004;13(3): 321-323.

37. Smith RV, Lofwall MR, Havens JR. Abuse and diversion of gabapentin among nonmedical prescription opioid users in Appalachian Kentucky. Am J Psychiatry. 2015;172(5):487-488.

38. Havens JR, Lofwall MR, Frost SD, Oser CB, Leukefeld CG, Crosby RA. Individual and network factors associated with prevalent hepatitis $\mathrm{C}$ infection among rural Appalachian injection drug users. Am J Public Health. 2013;103(1):e44-e52.

39. Baird CR, Fox P, Colvin LA. Gabapentinoid abuse in order to potentiate the effect of methadone: a survey among substance misusers. Eur Addict Res. 2014;20(3):115-118.

40. Schifano F, D’Offizi S, Piccione M, et al. Is there a recreational misuse potential for pregabalin? Analysis of anecdotal online reports in comparison with related gabapentin and clonazepam data. Psychother Psychosom. 2011;80(2):118-122.

41. Hakkinen M, Vuori E, Kalso E, Gergov M, Ojanpera I. Profiles of pregabalin and gabapentin abuse by postmortem toxicology. Forensic Sci Int. 2014;241:1-6.

42. Chiappini S, Schifano F. A decade of gabapentinoid misuse: an analysis of the European Medicines Agency's 'suspected adverse drug reactions' Database. CNS Drugs. 2016;30(7):647-654.

43. Bastiaens L, Galus J, Mazur C. Abuse of gabapentin is associated with opioid addiction. Psychiatr Q. 2016;87(4):763-767.

44. Kapil V, Green JL, Le Lait MC, Wood DM, Dargan PI. Misuse of the gamma-aminobutyric acid analogues baclofen, gabapentin and pregabalin in the UK. Br J Clin Pharmacol. 2014;78(1):190-191.

45. Prakash, Prabhu LV, Rai R, et al. Teratogenic effects of the anticonvulsant gabapentin in mice. Singapore Med J. 2008;49(1):47-53.

46. Afshar M, Golalipour MJ. Teratogenic effects of gabapentin on neural tube and limb development in mice. Neurosciences (Riyadh). 2008;13(3):321-323.

47. AfsharM,Hassanzadeh-TaheriMM,Moallem SA,TamiziA, GolalipourMJ. Teratogenic effects of gabapentin on the skeletal system of Balb/C mice fetuses. Neurosciences (Riyadh). 2009;14(3):239-244.

48. Catala Perez R, Gamez Lechuga M, Martinez-Lage Alvarez M, Anton Albisu A. Gabapentin-induced central hypoventilation. Med Clin (Barc). 2007;128(13):519.

49. Batoon SB, Vela AT, Dave D, et al. Recurrent hypoventilation and respiratory failure during gabapentin therapy. J Am Geriatr Soc. 2001; 49(4):498

50. Bekkelund SI, Lilleng H, Tønseth S. Gabapentin may cause reversible visual field constriction. BMJ. 2006;332(7551):1193.

51. Tuccori M, Lombardo G, Lapi F, Vannacci A, Blandizzi C, Del Tacca M. Gabapentin-induced severe myopathy. Ann Pharmacother. 2007;41(7):1301-1305.

52. Lipson J, Lavoie S, Zimmerman D. Gabapentin-induced myopathy in 2 patients on short daily hemodialysis. Am J Kidney Dis. 2005; 45(6):E100-E104.

53. Tandon VR, Mahajan V, Gillani ZH, Mahajan A. Pregabalin-induced self-harm behavior. Indian J Pharmacol. 2013;45(6):638-639.

54. Patorno E, Bohn RL, Wahl PM, et al. Anticonvulsant medications and the risk of suicide, attempted suicide, or violent death. JAMA. 2010; 303(14):1401-1409.

55. Andersohn F, Schade R, Willich SN, Garbe E. Use of antiepileptic drugs in epilepsy and the risk of self-harm or suicidal behaviour. Neurology. 2010;9(75):335-340.

56. Gibbons RD, Hur K, Brown CH, Mann JJ. Gabapentin and suicide attempts. Pharmacoepidemiol Drug Saf. 2010;19(12):1241-1247.
57. Finsterer J, Zarrouk Mahjoub S. Mitochondrial toxicity of antiepileptic drugs and their tolerability in mitochondrial disorders. Expert Opin Drug Metab Toxicol. 2012;8(1):71-79.

58. Sihoe AD, Lee TW, Wan IY, Thung KH, Yim AP. The use of gabapentin for post-operative and post-traumatic pain in thoracic surgery patients. Eur J Cardiothorac Surg. 2006;29(5):795-799.

59. Petrere JA, Anderson JA. Developmental toxicity studies in mice, rats, and rabbits with the anticonvulsant gabapentin. Fundam Appl Toxicol. 1994;23(4):585-589.

60. Montouris G. Gabapentin exposure in human pregnancy: results from the Gabapentin Pregnancy Registry. Epilepsy Behav. 2003;4(3): 310-317.

61. Verrotti A, Mencaroni E, Castagnino M, Zaccara G. Foetal safety of old and new antiepileptic drugs. Expert Opin Drug Saf. 2015;14(10): $1563-1571$

62. Hill DS, Wlodarczyk BJ, Palacios AM, Finnell RH. Teratogenic effects of antiepileptic drugs. Expert Rev Neurother. 2010;10(6):943-959.

63. Ramsay RE. Gabapentin toxicity. In: Levy RH, Mattson RH, Meldrum BS, editors. Antiepileptic Drugs. 4th ed. New York: Raven Press; 1995: 857-860.

64. McLean MJ, Morrell MJ, Willmore LJ, et al. Safety and tolerability of gabapentin as adjunctive therapy in a large, multicenter study. Epilepsia. 1999;40(7):965-972.

65. Canadillas-Hidalgo FM. The safety and tolerability profile of gabapentin in optimal doses. Rev Neurol. 2004;39(4):371-380.

66. Comoglu T. The influence of administration route in the comparison of dosage forms. Arch Trauma Res. 2013;2(1):58-59.

67. Aulton ME. Pharmaceutics: The Science of Dosage Form Design. Edinburgh; New York: Churchill Livingstone. 2002:197-210.

68. Jankovic SM, Dostic M. Choice of antiepileptic drugs for the elderly: possible drug interactions and adverse effects. Expert Opin Drug Metab Toxicol. 2012;8(1):81-91.

69. Patsalos PN. Drug interactions with the newer antiepileptic drugs (AEDs)--part 1: pharmacokinetic and pharmacodynamic interactions between AEDs. Clin Pharmacokinet. 2013;52(11):927-966.

70. Diaz RA, Sancho J, Serratosa J. Antiepileptic drug interactions. Neurologist. 2008;14(6 suppl 1):S55-S65.

71. Johannessen Landmark C, Patsalos PN. Drug interactions involving the new second- and third-generation antiepileptic drugs. Expert Rev Neurother. 2010;10(1):119-140.

72. Lukawski K, Swiderska G, Czuczwar SJ. Effect of combined treatment with diuretics and gabapentin on convulsive threshold in mice. Acta Pol Pharm. 2013;70(1):147-152.

73. Eldon MA, Underwood BA, Randinitis EJ, Sedman AJ. Gabapentin does not interact with a contraceptive regimen of norethindrone acetate and ethinyl estradiol. Neurology. 1998;50(4):1146-1148.

74. Radulovic LL, Wilder BJ, Leppik IE, et al. Lack of interaction of gabapentin with carbamazepine or valproate. Epilepsia. 1994;35(1):155-161.

75. Hooper WD, Kavanagh MC, Herkes GK, Eadie MJ. Lack of a pharmacokinetic interaction between phenobarbitone and gabapentin. $\mathrm{Br} J$ Clin Pharmacol. 1991;31(2):171-174.

76. Luszczki JJ. Isobolographic analysis of interaction between drugs with nonparallel dose-response relationship curves: a practical application. Naunyn Schmiedebergs Arch Pharmacol. 2007;375(2):105-114.

77. Papathanasiou T, Juul RV, Gabel-Jensen C, Kreilgaard M, Lund TM. Population pharmacokinetic modelling of morphine, gabapentin and their combination in the rat. Pharm Res. 2016;33(11):2630-2643.

78. Papathanasiou T, Juul RV, Heegaard AM, Kreilgaard M, Lund TM. Co-administration of morphine and gabapentin leads to dose dependent synergistic effects in a rat model of postoperative pain. Eur J Pharm Sci. 2016;82:97-105.

79. Eckhardt K, Ammon S, Hofmann U, Riebe A, Gugeler N, Mikus G. Gabapentin enhances the analgesic effect of morphine in healthy volunteers. Anesth Analg. 2000;91(1):185-191.

80. Lukawski K, Janowska A, Jakubus T, Raszewski G, Czuczwar SJ. Combined treatment with gabapentin and drugs affecting the renin-angiotensin system against electroconvulsions in mice. Eur J Pharmacol. 2013;706(1-3):92-97. 
81. Borobia-Perez AM, Fernandez-Capitan C, Carcas-Sansuan AJ. Psicosis, alucinaciones visuales y deterioro de la función renal secundarias a la interacción gabapentina-morfina [Psychosis, visual hallucinations and worsening renal function due to a gabapentine-morphine interaction]. Rev Neurol. 2008;47(6):332-333. Spanish.

82. Goel R, Goel A, Kumar Y. Influence of carvedilol on anticonvulsant effect of gabapentin. Acta Neurol Belg. 2011;111(4):296-305.

83. Granados-Soto V, Arguelles CF. Synergic antinociceptive interaction between tramadol and gabapentin after local, spinal and systemic administration. Pharmacology. 2005;74(4):200-208.

84. Ortega-Varela LF, Herrera JE, Medina-Santillan R, Reyes-Garcia G, Rocha-Gonzalez HI, Granados-Soto V. Synergistic interaction between gabapentin and metamizol in the rat formalin test. Proc West Pharmacol Soc. 2004;47:80-83.

85. Rizwan AN, Ali A, Dua Y, Pal SN, Pillai KK. Effects of gabapentin and antidepressant drug combinations on convulsions and memory in mice. Pol J Pharmacol. 2003;55(6):965-971.

86. Sanchez-Romero A, Duran-Quintana JA, Garcia-Delgado R, MargaritoRangel C, Poveda-Andres JL. Possible gabapentin phenytoin interaction. Rev Neurol. 2002;34(10):952-953.

87. Nevin RL, Pietrusiak PP, Caci JB. Prevalence of contraindications to mefloquine use among USA military personnel deployed to Afghanistan. Malar J. 2008;7:30.

88. Franco-Perez J, Ballesteros-Zebadua P, Manjarrez-Marmolejo J. Anticonvulsant effects of mefloquine on generalized tonic-clonic seizures induced by two acute models in rats. BMC Neurosci. 2015;16:7.

89. Yagi T, Naito T, Mino Y, Umemura K, Kawakami J. Impact of concomitant antacid administration on gabapentin plasma exposure and oral bioavailability in healthy adult subjects. Drug Metab Pharmacokinet. 2012;27(2):248-254.
90. Richens A. Clinical pharmacokinetics of gabapentin. In: Chadwick D, editor. New Trends in Epilepsy Management: The Role of Gabapentin. London, UK: Royal Society of Medicine Service; 1993:41-46.

91. Shemenski J. Cimetidine as a novel adjunctive treatment for early stage Lyme disease. Med Hypotheses. Epub 2016 Apr 9.

92. Hurley RW, Chatterjea D, Rose Feng M, Taylor CP, Hammond DL. Gabapentin and pregabalin can interact synergistically with naproxen to produce antihyperalgesia. Anesthesiology. 2002;97(5):1263-1273.

93. Duggan KC, Walters MJ, Musee J, et al. Molecular basis for cyclooxygenase inhibition by the non-steroidal anti-inflammatory drug naproxen. J Biol Chem. 2010;285(45):34950-34959.

94. Joel JJ, Musthafa MM, Shastry CS. A study on drug related problems and pharmacist intervention in patients undergoing haemodialysis in a tertiary care hospital. Int Res J Pharm App Sci. 2013;3(5): 263-265.

95. Garg JP, Chasan-Taber S, Blair A, et al. Effects of sevelamer and calcium-based phosphate binders on uric acid concentrations in patients undergoing hemodialysis: a randomized clinical trial. Arthritis Rheum. 2005;52(1):290-295.

96. Boneva N, Brenner T, Argov Z. Gabapentin may be hazardous in myasthenia gravis. Muscle Nerve. 2000;23(8):1204-1208.

97. Koide Y, Ikeda H, Inoue Y. Development or worsening of myoclonus associated with gabapentin therapy. Rinsho Shinkeigaku. 2009;49(6): 342-347.

98. United States National Library of Medicine. Act Gabapentin. Available from: http://pubchem.ncbi.nlm.nih.gov/summary/summary. cgi? sid=46506529\#x400. Accessed June 1, 2016.

99. United States National Library of Medicine. Drug Information Portal. Available from: https://druginfo.nlm.nih.gov/drugportal/name/gabapentin. Accessed June 1, 2016.
Journal of Experimental Pharmacology

\section{Publish your work in this journal}

The Journal of Experimental Pharmacology is an international, peerreviewed, open access journal publishing original research, reports, reviews and commentaries on all areas of laboratory and experimental pharmacology. The manuscript management system is completely online and includes a very quick and fair peer-review system.

\section{Dovepress}

Visit http://www.dovepress.com/testimonials.php to read real quotes from published authors. 